operators, and the permanancy of the standard, even under exceptionally unfavorable conditions, which has far exceeded anything for which we dared to hope when the standard was first used, have abundantly demonstrated its utility; and in view of the ease and accuracy with which it is possible to compare directly the colors of natural waters with metallic solutions, which are, in fact, the only reliable ultimate standards now in use or known, it seems most unfortunate and in every way undesirable to introduce arbitrary go-betweens, not having definite values of their own or capable of being reproduced or controlled except by comparison with other standards.

\title{
TECHNICAL ANALYSIS OF ASPHALTUM. No. 2.'
}

BY LaURA A. LintoN.

Received January 3, reg6.

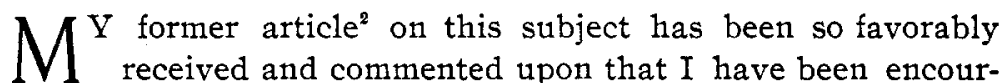
aged to offer a second contribution with the object of adding a few more facts to the literature of the subject, as well as to point out certain changes in the method of analysis outlined in the first article, which changes have been suggested by recent analytical work.

The method universally employed for the determination of the incorporated water of asphaltum is that of estimating the loss in weight of the substance when exposed to a temperature of $100^{\circ}$ C. The possibility of a loss of more or less of the inherent volatile matter when heated to such a high temperature must have occurred to every one engaged in the analysis of asphaltum. A series of experiments made during the past few months has confirmed my suspicion that such is the case.

The experiment proper consisted in heating a weighed portion of asphaltum in a combustion tube, the general arrangement of the apparatus being the same as that employed in the determination of water in organic analysis. The temperature was gradually raised from the temperature of the room to that of boiling water. The tube was swept out before and after heating with either dried air or dried hydrogen. Simultaneously with

1 Read at the Cleveland meeting, December 3I, I895.

2 This Journal, r6, 809 . 
this experiment two other weighed portions of the same asphaltum were dried, one in an oven at $100^{\circ} \mathrm{C}$. to serve as a check upon that portion dried in the combustion tube, while the other portion was dried in the sun.

As the method of sun drying requires several days it was done in a room as free as possible from dust and, to increase the temperature and at the same time to exclude all foreign matter, the samples were placed in large watch glasses with watch-glass covers fitting loosely to allow of circulation of air. In this lenslike arrangement the maximum temperature did not exceed $50^{\circ}$ C. On cloudy days the drying was necessarily done in the oven below $50^{\circ} \mathrm{C}$.

These experiments showed that the asphaltum tested did not oxidize below $100^{\circ} \mathrm{C}$., as aspiration with dried air and dried hydrogen gave the same results; and also that all moisture is driven off below $50^{\circ} \mathrm{C}$, while between $50^{\circ} \mathrm{C}$. and $100^{\circ} \mathrm{C}$., a certain portion of oily matter is lost, this oil invariably collecting in drops about the mouth of the combustion tube. In the light of these facts it becomes clear that the old method of determining moisture, if it is to be determined at all, is incorrectsince the percentage lost on heating the asphaltum to $100^{\circ} \mathrm{C}$. includes not only the water but also that part of the petrolene volatile below $100^{\circ} \mathrm{C}$.

The moisture associated with an asphaltum being hygroscopic, as is evident from the fact that the same specimen carries a constantly varying proportion depending on atmospheric conditions, it should never be estimated as a constituent part of the asphaltum, particularly in making analyses for purposes of comparison.

In making all of my recent analyses, as a preliminary, $I$ have air dried to a constant weight several grams of the sample to be analyzed before weighing out the portion to be treated with the different solvents, thus entirely excluding water from the percentage composition of the asphaltum.

A second departure from the method previously given is a purely mechanical one. As a matter of convenience I have discarded the use of the Erlenmeyer flask, the substance being weighed out on balanced filter-papers instead. In this way all digestion is done in separatory funnels. This method of treat- 
ment is very simple and the results obtained are good, but care must be taken that the solution in the funnels does not become too concentrated before running off through the tap, otherwise the petrolene precipitates itself, more or less of it adhering to the outside of the filter-paper. To prevent this the petroleum ether may be drawn off every few minutes until the greater part of the petrolene has been extracted after which it is perfectly safe to allow the digestion to continue for hours in removing the final traces.

Lastly, I have obtained some interesting and, in my opinion, important results by fractionating the asphaltene, determining it in two portions: that soluble in boiling turpentine and that soluble only in chloroform. The process is a very tedious one on account of the difficulty of removing the very last trace soluble in boiling turpentine, but the results that follow are a sufficient warrant for the expenditure of so much time, which, for the specimens analyzed, ranged from one to four weeks. In order to secure concordant results in duplicate analyses $I$ found it necessary to pursue the following course:

After the removal of the petrolene the residue on the filter was digested in boiling turpentine until the filtrate was colorless, when the contents of the filter were washed in alcohol and dried at $100^{\circ} \mathrm{C}$. If, on drying, a black, semi-liquid substance separated from the mass, this was an indication that the turpentine fraction had not been entirely removed, in which case the process was repeated. In the most refractory specimens this treatment was applied many times. The tardy yielding to the solvent power of the turpentine is doubtless largely due to the fact that the turpentine does not readily penetrate the mass and it may be, also, that the chloroform fraction prevents the action of the turpentine just as gold protects silver from the action of nitric acid. The completion of the process is always indicated by the appearance of the dried residue which, after the complete removal of the turpentine fraction, is invariably a loose, brown powder without coherence. This treatment shows that part of the asphaltene soluble in boiling turpentine to be a black, viscous, semi-liquid substance resembling tar and having a melting point at or below $100^{\circ} \mathrm{C}$. 
Another fact, which may prove valuable as well as interesting, is clearly brought out in this fractionation of asphaltene and that is that not only do the "aged" varieties of asphaltum contain a larger percentage of asphaltene but the turpentine fraction becomes a smaller proportion of the total bitumen while the chloroform fraction becomes larger.

An investigation of the table of the percentage composition of the following varieties of asphaltum will confirm this statement:

No. I. An average sample of land asphaltum from the island of Trinidad.

No. 2. Altered or "aged" (iron pitch) Trinidadland asphaltum.

No. 3. Altered or "aged" Trinidad land asphaltum.

No. 4. An average sample of Trinidad lake asphaltum.

No. 5. An altered or "aged" Trinidad lake asphaltum.

No. 6. An altered or "aged" Trinidad lake asphaltum.

No. 7. An altered or "aged" (iron pitch) Trinidad lake asphaltum.

No. 8. Asphaltum from Montague Co., Texas.

No. 9. Turrellite from Uvalde Co., Texas.

No. 1o. Asphaltum from near Ardmore, Indian Ter.

No. I I. Grahamite from Ritchie Co., W. Va.

No. I2. Scyssel asphaltic rock from Eastern France.

\begin{tabular}{|c|c|c|c|c|c|c|c|c|}
\hline $\begin{array}{l}\text { Sam } \\
\text { ple. }\end{array}$ & trolene. & $\begin{array}{l}\text { Turpel1- } \\
\text { tine } \\
\text { fraction. }\end{array}$ & $\begin{array}{l}\text { Chloroforn } \\
\text { fractionl. }\end{array}$ & "Asphal- & $\begin{array}{c}\text { Iotal } \\
\text { bitumetr. }\end{array}$ & $\begin{array}{l}\text { Ratio of } \\
\text { chloroform } \\
\text { fraction to } \\
\text { total } \\
\text { bitumen. }\end{array}$ & $\begin{array}{c}\text { Organic } \\
\text { matter } \\
\text { not } \\
\text { bitumen. }\end{array}$ & $\begin{array}{l}\text { Mineral } \\
\text { matter. }\end{array}$ \\
\hline I & 33.73 & 15.67 & $3 \cdot 179$ & I 8.849 & 52.579 & I : I6 & I I. 528 & 35.886 \\
\hline 2 & 33.574 & $13 \cdot 7$ & 9.627 & 23.327 & $56.90 \mathrm{r}$ & $1: 6$ & $8.4 \mathrm{I} 4$ & 584 \\
\hline 3 & $21 \cdot 362$ & $\mathrm{I}_{5} .2$ & I 5. I I 2 & 30.312 & 51.674 & I $: 3$ & 9.85 & 38.375 \\
\hline 4 & 35.40 & I 2.300 & 5.287 & 17.587 & 52.987 & I : 10 & 10.962 & 00 \\
\hline 5 & 26.925 & 18.613 & 6.687 & $25 \cdot 3$ & 52.225 & I : 8 & II, 237 & 36.537 \\
\hline 6 & 19.25 & 22.35 & 10.962 & 33.312 & 52.562 & I : 5 & $9 \cdot 562$ & 37.875 \\
\hline 7 & 22.25 & $9 \cdot 785$ & I 2.54 & 22.325 & 44.575 & $I: 4$ & 8.937 & 46.462 \\
\hline 8 & $7 \cdot 53^{8}$ & ז.601 & trace & 1.601 & & $\ldots$ & $\cdots$ & $90.86 \mathrm{I}$ \\
\hline 9 & 8.786 & 3.267 & trace & 3.267 & 12.053 & $\cdots$ & $\cdots$ & 87.947 \\
\hline IO & 9.503 & 0.9905 & trace & 0.9905 & I. 0.4935 & $\ldots$ & $\cdots$ & 89.5065 \\
\hline I I & 49.959 & I $7 \cdot 45^{8}$ & 32.583 & $50.04 \mathrm{I}$ & 100,00 & $I: 3$ & $\cdots$ & $\cdots$ \\
\hline 12 & $7 \cdot 486$ & 3.945 & 0.371 & 4.316 & I 1.802 & $I: 3 I$ & $\cdots$ & 88.198 \\
\hline
\end{tabular}

I am not yet prepared to say that the turpentine fractionation of asphaltene, if made in the case of the asphaltum obtainable from 
different parts of the world would indicate the relative "ageing" of the different varieties, but my experience with Trinidad Pitch inclines me to think that this will prove the case when such analyses are made. However, even if the turpentine determination should prove of no value as indicative of "ageing" processes in asphaltum, there is still a weighty reason why it should not be abandoned.

The marked physical difference between the turpentine and chloroform fractions would seem to indicate the probability of a chemical difference and I am sure that when an ultimate analy. sis of asphaltum has been made, as it will be in the near future, that turpentine as a solvent will be proven to have its place.

I am aware that some object to the use of turpentine because it is not pleasant to work with, particularly when it is boiling hot, but in scientific research we are seeking truth and not our own pleasure and convenience. If the cooperation of chemists engaged in the investigation of asphaltum could but be secured the solution of the problem would be a speedy one. But this may not be, so solvents are accepted or rejected at will with apparently no principle ruling in the choice. One chemist of wide reputation rejects chloroform and uses carbon disulphide as the final solvent in the extraction of bituminous matter.

I have analyzed many different varieties of American and foreign asphaltum and, with the exception of the Neufchatel, which is practically all petrolene, and the asphaltum from Texas and Indian Territory, all yielded more or less bituminous matter on treatment with chloroform after exhaustion with other solvents. Now, because the Neufchatel and a few other varieties need no chloroform for the extraction of bitumen, shall this solvent be stricken from our category? rather let our scheme be so broadened as to be applicable to every variety of asphaltum the earth holds.

tintersity of Michigas.

DISCUSSION.

A. H. Sabin: This asphaltum business is one of a great deal of commercial importance. There are a great many things about it that we do not know: I hope somebody here can tell us a few things. 
In the first place asphalts are a very peculiar set of bodies. The most attention has been given of late years to Trinidad, because it has been used for paving purposes, and has been of immense commercial importance. It has generally been overlooked by the chemists who have worked on this line, that comparatively recently the commercial introduction of asphalts from other sources has been of great importance. Ordinarily chemists analyze either the Trinidad or Egyptian asphalts. The Egyptian asphalt is considered to be a representative of the high grade asphalts which are to be found in the East, while the Trinidad asphalt is a cheaper variety, very elastic, and contains a large amount of foreign matter. Commercially, as a matter of fact, the Egyptian asphalt is higher priced than the American, and so are all the Eastern asphalts. The fact has been known for a number of years that large deposits of asphalt are found in Utah and Colorado known as Gilsonite and Uintahite. These have been put on the market at such low prices that in St. Louis, I understand, Gilsonite is used in the paving trade. Gilsonite is an exceedingly pure asphalt. It is a very interesting substance, and it is to be hoped that future investigations will take into consideration the fact that these more recently discovered beds, which promise to be of more commercial importance than the Trinidad deposits, are practically inexhaustible. Some asphalt deposits are being developed in South America. We have the general statement made in Dana's Mineralogy, which so far as I can learn is based upon the well known investigations made long ago in France, and partly on some work chiefly in the line of checking results, which was done in the Sheffield Scientific School, that all petroleums contain more or less asphalt in solution, and that it is generally believed that asphalts are a sort of petroleum residue, and that the natural asphalts differ from the asphalts which are obtained as petroleum residues in being oxidized compounds. As near as I can find out that term "oxidized" is merely a conventional term. It means that the hydrogen has been removed, not that the oxygen has been added, although they show upon analysis that some oxygen is present. The chief difference apparently is that compounds containing hydrogen have escaped. The differ- 
ence between hard and soft asphalts is just that difference that the mineral oils have been removed in some way or other from the asphalts and they are therefore hard; whereas some of them like the Trinidid have a considerable amount of mineral oily matter in them and are very elastic and well adapted to paving purposes. The presence of these ingredients, while it adds to their durability, detracts from their usefulness for other technical purposes, because mineral oil is comparatively easily removed by the action of the weather, while the hard asphalts not containing this volatile and soluble matter can be made elastic by being compounded with linseed oil and other substances, and in that way can be made immensely more permanent than elastic asphalts. This is inapplicable to paving, but it has large application. There is a good deal of commercial asphalt on the market under the name of Maltha, which was used as long ago as the time of Pliny. The name has been applied recently to asphalt from southern California. It is obtained in various degrees of hardness from a thick liquid to a solid, and is a good illustration of the so-called artificial asphalts. Of course, it is a natural product. Nothing has been done to it except the volatile portions have been distilled out of it. I should like to know whether these asphaltic constituents are present in all petroleums, or whether they are in some cases or in all cases produced by the action of high temperature upon the crude oil, and whether these differ from natural asphalt in oxidation or in what way?

Prof. Mabery: I have had some experience with asphalts in the way of observation, and to a certain extent experimentally. At Oil Springs, in Canada, a surface oil is found that is very heavy, with a specific gravity of go, and in the vicinity of beds of asphaltic pitch. There is no question that there has been a change through the heavy surface oil into the asphalt. Some constituents of petroleum are very unstable; for example, at a temperature of $80^{\circ}$, in vacuo, a distillate was collected, which, after standing two years and then again distilled, decomposed into tar which could not be distilled without carbonization, doubtless the result of polymerization.

In regard to the origin of petroleum there is a great deal of 
conjecture. So far as oxidation is concerned, the amount of oxygen contained in it is small. Recently we examined a product made from petroleum residue which resembles in some respects natural asphalt. It may be that some of you have heard of it under the name of Byerlyte. It is manufactured in this city. The process consists in taking the heavy oil after the burning oil is distilled, putting it into the still, passing in currents of air and applying a gentle heat to the bottom of the still during five or six days. Then the product is drawn off. It contains no fixed carbon. It resembles in some respects natural Gilsonite. So far as practical uses are concened they are closely related. With reference to oxidation the quantity of oxygen does not appear to be very different from that in crude oil. As Mr. Sabin suggests, we cannot look upon oxidation in the production of asphalt as the introduction of oxygen, but rather as the removal of hydrogen, and that is doubtless related. to certain features of polymerization. It seems to be a conversion of the unstable hydincarbons into higher products. Concerning the composition of these products we know very little.

Other products have come under my observation which are on the market at the present time and used for insulators.

In some heavier sludges polymerization takes place when substances are formed closely resembling asphalt. There is a great field of investigation surrounding asphalt, but it is an exceedingly difficult subject.

The determination of water is an interesting question. It is practically impossible to remove water from petroleum by the ordinary methods. Ohio and Canada petroleum may stand for months, and when it is again distilled, water will appear to a considerable extent. Those pure hydrocarbons, which I showed last evening, can not be dried with calcium chloride. We found the moisture could only be removed by sodium, and after it is removed, upon exposure to the air, it reabsorbs moisture with great rapidity. Probably the same thing would apply to asphalt. Of course, in heating, the water will be removed, but if the products are again exposed to the air they will reabsorb the water. This question should be undertaken from the standpoint of thorough chemical investigation. 
Mr. Sabin: These artificial asphalts have some very remarkable commercial differences from the natural asphalts. For example, they resist the action of sodium hydroxide. Sodium hydroxide seems to combine with almost all natural asphalts, but not with pitches or tars. In the same way for the purpose for which I use it, it is impossible to use it as asphalt, or in the way in which you can use any natural asphalt. You can not melt it alone without decomposition. It can be melted with other substances, such as rosin or some mineral oils. But it does not mix with the vegetable oils, such as linseed by itself. It is used very successfully as an insulator, as many of the pitches are. It has many useful and valuble qualities, which none of the asphalts have, especially that of resisting caustic alkali, but for many purposes it differs as widely from natural asphalt as if it were entirely and absolutely a different substance.

\section{REVIEWS.}

\section{THE VALENCY OF OXYGEN AND THE STRUCTURE OF COMPOUNDS CONTAINING IT.}

Hydrogen Dioxide.-In a recent issue of the Berichte der deutschen chemischen Gesellschaft ${ }^{1} \mathrm{~J}$. W. Brïhl calls attention to the significance of recent work of Moritz Traube upon the structural formula of hydrogen peroxide. Traube found that when, in the electrolysis of water, the electrodes are separated by a diaphragm, no hydrogen peroxide forms. If now air be blown through the solution in contact with the cathode, hydrogen peroxide forms in quantity, presumably by the oxidation of the nascent hydrogen by the molecular oxygen of the air. Traube has also shown that when silver oxide is reduced to metal with formation of water and free oxygen, the latter comes from the peroxide, the oxygen of the water coming from the silver oxide, thus :

$$
\mathrm{Ag}_{2} \mathrm{O}+\mathrm{H}_{2} \mathrm{O}_{2}=\mathrm{Ag}_{2}+\mathrm{H}_{2} \mathrm{O}+\mathrm{O}_{2} \text {. }
$$

The constitutional symbol of hydrogen peroxide is usually written H.O.O.H. If this be correct we should expect it to unite with the olefines forming glycols by direct addition. Glycols seem not to be formed in this way, except in the case of 